\title{
Parque Nacional do Monte Roraima: conflitos no uso e produção do território
}

\section{Monte Roraima National Park: conflicts in the use and production of the territory}

Oséias Cordeiro Sartori - Mestre em Geografia pela Universidade Federal de Roraima (UFRR).E-mail: oseias.sartori@gmail.com

Maria Bárbara Magalhães Bethonico - Doutorado em Geografia e Ordenamento Territorial pela Universidade Federal Fluminense (UFF). Professora da Universidade Federal de Roraima (UFRR). E-mail: maria.bethonico@ufrr.br

\section{Resumo}

O presente estudo prioriza as análises dos conflitos decorrentes da criação de uma unidade de conservação de proteção integral em território indígena. Fundamentando-se no conceito de território como categoria de análise, o caso da dupla afetação envolvendo o Parque Nacional do Monte Roraima e a Terra Indígena Raposa Serra do Sol-Roraima foi utilizado como suporte às discussões. A construção da reflexão foi possibilitada pelo cruzamento de informações oriundas de levantamento bibliográfico, análise documental, entrevistas e observações. Os resultados indicaram que as restrições impostas às negociações dificultam $\mathrm{o}$ estabelecimento de parcerias, suscitando o desenvolvimento de um instrumento de gestão de conflitos capaz de comportar interesses diversos e permitir o livre exercício da autonomia dos sujeitos envolvidos.

\section{Palavras-chave}

Território. Terras Indígenas. Unidades de Conservação. Conflitos.

\begin{abstract}
The present study gives priority to analysis of the conflict resulting from the creation of a total protection conservation unit in merindian's territory. Based on the concept of the territory as category of analysis, in case of a double presumption involving the Monte Roraima National Park and the Amerindian's Land Raposa Serra do Sol-Roraima was utilized to support to the discussions. The construction of the reflection was possible by crossing information from bibliographical research, documentary analysis, interviews and observations. The results indicated that the restrictions made the negotiations difficult partnership establishments, leading to the development of an instrument of management of conflicts able to contain different interests, permitting free practice autonomy of the subjects involved.
\end{abstract}

\section{Keywords}

Territory.

Amerindians

Lands. Conservation Units. Conflicts. 


\section{INTRODUÇÃO}

A perspectiva do desenvolvimento deste estudo aponta para a construção de uma reflexão a respeito dos conflitos decorrentes das sobreposições territoriais entre unidades de conservação de proteção integral e terras indígenas. Nesta esteira, a situação de dupla afetação entre o Parque Nacional do Monte Roraima (PNMR) e a Terra Indígena Serra do Sol (TIRSS) foi utilizada como suporte às discussões propostas.

Ao resultar das iniciativas do poder público, a sobreposição mencionada encontra suas raízes em critérios políticos e geopolíticos incorporados ao processo de expansão da fronteira preservacionista. O PNMR, criado pelo Decreto $\mathrm{n}^{\circ}$ 97.887, de 28 de junho de 1989, localiza-se no interior da TIRSS, mais especificamente no território do povo Ingarikó.

As ações impositivas propiciadas por uma atitude de invisibilização contra o povo Ingarikó excluíram a participação dos indígenas no processo de criação do PNMR e ensejaram o surgimento de tensões que se prolongaram no tempo, alcançando os dias atuais. Os conflitos resultantes desse processo foram estabelecidos por questões legais e culturais, distintos interesses e obstáculos ao processo de negociação entre as partes envolvidas.

Essas configurações da realidade suscitaram o objetivo de analisar os conflitos decorrentes da criação do PNMR em território indígena. Como resultado de uma pesquisa de mestrado, esse estudo tem sua importância associada à necessidade de reflexões a respeito das sobreposições entre unidades de conservação de proteção integral e territórios indígenas, situações cada vez mais frequentes no país.

A pesquisa se baseou em um levantamento bibliográfico a partir do conceito de território, sendo este capaz de permitir a análise dos aspectos políticos e culturais relacionados com os distintos interesses dos sujeitos envolvidos. As discussões propostas resultaram do cruzamento de informações oriundas da bibliografia, análise documental, entrevistas e observações. Os documentos acessados foram o plano de manejo do PNMR, contido em Brasil (2000), o compêndio denominado SOS Monte Roraima, disposto em Brasil (2004), o Plano de Administração Conjunta, conforme Brasil (2008), e os relatórios das assembleias gerais do povo Ingarikó. Também foram realizadas quinze entrevistas, sendo treze com o povo Ingarikó e duas com servidores do Instituto Chico Mendes de Conservação da Biodiversidade/ICMBio e da Fundação Nacional do Índio/FUNAI. Para ampliar o entendimento do território Ingarikó, foram realizadas nove expedições de campo nas comunidades Serra do Sol, Manalai, 
Caramambatai, Awendei, Sauparu, Mapaé, Kumaipá, no período compreendido entre setembro de 2011 e setembro de 2012. Além de visitas ao território, as observações também foram realizadas nas casas de apoio do povo Ingarikó na cidade de Boa Vista/RR, no mesmo período mencionado.

\section{A ÁREA DE ESTUdO: LIMITES DO PARQUE NACIONAL DO MONTE RORAIMA}

Segundo Brasil (1989), o PNMR localiza-se entre as coordenadas geográficas $04^{\circ} 48^{\prime}$ a $05^{\circ} 16^{\prime}$ - Latitude Norte e 6005' a $60^{\circ} 44$ - Longitude Oeste (Figura 1). Trata-se de uma unidade de conservação de proteção integral totalmente inserida no território do povo Ingarikó, nos limites da TIRSS, município de Uiramutã, estado de Roraima. Com uma paisagem composta por escarpas imponentes, principalmente na região fronteiriça com a Venezuela, o PNMR possui algumas nascentes dos rios que fazem parte da bacia hidrográfica do rio Branco, como o Cotingo e o Maú que integram a sub-bacia do rio Tacutu, um dos formadores do rio Branco. Aliados aos relevos tabulares, esses rios possuem níveis de significância que extrapolam os critérios ecológicos. Além da importância como unidades da paisagem, são considerados indispensáveis para a manutenção das comunidades indígenas.

Figura 1 - Localização da área de estudo

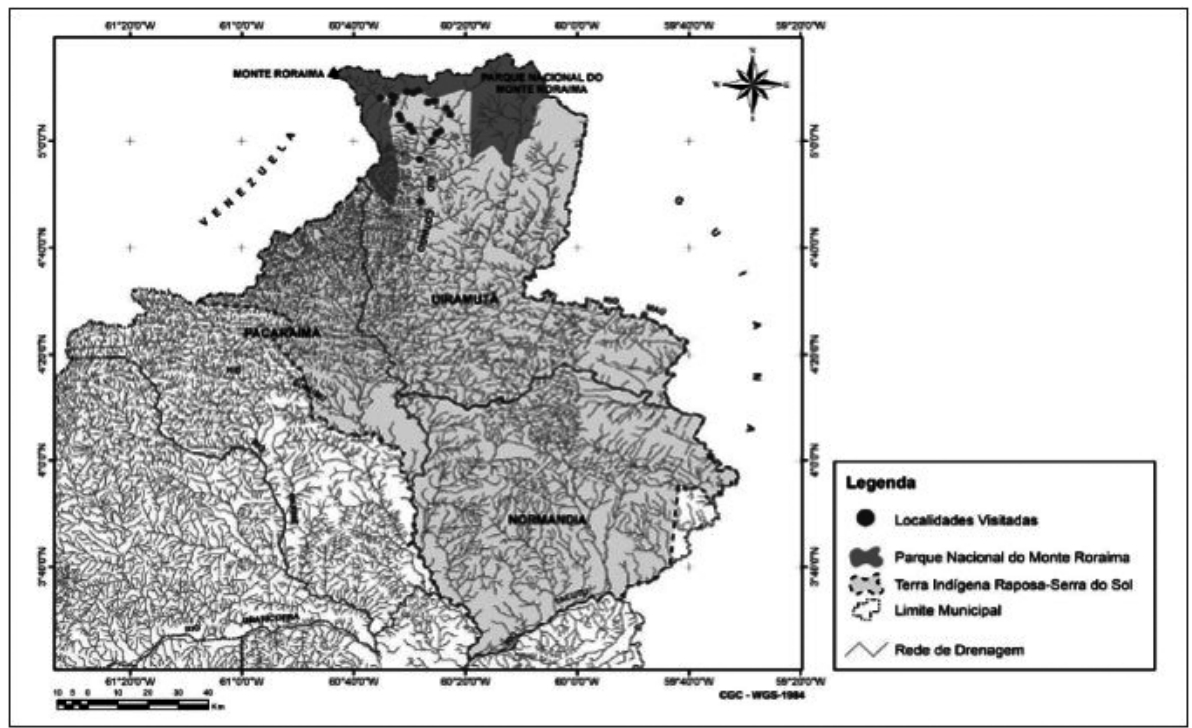

Fonte: IBGE (2010). Elaboração: Franzmiller Almeida Nascimento. 
Conforme Farage (1991), as evidências da ocupação humana na região remontam a períodos anteriores à Era Cristã. Mesmo corroborando as afirmações anteriores, Frank (2007) acrescenta outras possibilidades de ocupação ao se referir às proximidades do Monte Roraima. A primeira delas faz referência a um período aproximado de dois mil anos, protagonizada por ancestrais Pemon-Kapon oriundos da parte central do Escudo das Guianas. A segunda possibilidade aponta para o ano de 1492, por ocasião do processo de fuga da perseguição espanhola. A despeito das possibilidades, Nabuco (1949) ressalta a existência de registros da ocupação indígena na literatura desde o ano de 1810.

A despeito da antiguidade da ocupação indígena, o povo Ingarikó começou a ser mencionado em documentos oficiais a partir do século XX, em publicações como a de Koch-Grunberg (2006). Segundo o autor, os indivíduos pertencentes ao grupo linguístico Kapon, no qual se inclui os Ingarikó, sempre viveram ao redor do Monte Roraima. Embora tenham construído toda a sua história no território mencionado, o poder público agiu como se esses indígenas não ocupassem a área pretendida para a criação do PNMR, configurando uma atitude de invisibilização.

\section{MULTITERRITORIALIDADE NA ÁREA DO PARQUE NACIONAL DO MONTE RORAIMA}

As abordagens sobre as distintas dimensões de território suscitam, inicialmente, uma diferenciação entre os conceitos de território e espaço. Ao considerar o espaço como totalidade, Santos (2008) reporta-se à amplitude do conceito, destacando-o como o mais abrangente. Como portador de representações e realidades, o espaço pode ser caracterizado pela capacidade de envolver as demais categorias, além dos diversos componentes.

Raffestin (1993) destaca que o espaço é anterior ao território. A apropriação de um espaço por determinado indivíduo ou grupo constitui um ato territorializador. A pré-existência do espaço a qualquer ação transforma-o em território tão logo seja manifestada sobre ele uma intenção de apoderamento. No caso específico deste estudo, as abordagens suscitam uma variedade de perspectivas. Ressalta-se, portanto, a opção pela utilização das quatro dimensões do território abordadas por Haesbaert (2010, p. 40):

Jurídico-política (relativa também a todas as relações espaço-poder institucionalizadas) a mais difundida, onde o território é visto como um espaço delimitado e controlado, através do qual se exerce um determinado poder, na maioria das vezes - mas não exclusivamente - relacionado ao poder político do Estado. 
Cultural (muitas vezes culturalista) ou simbólico-cultural: prioriza a dimensão simbólica e mais subjetiva, em que o território é visto, sobretudo, como o produto da apropriação/valorização simbólica de um grupo em relação ao seu espaço vivido.

Econômica [...] menos difundida, enfatiza a dimensão espacial das relações econômicas, o território como fonte de recursos.

Natural, uma noção de território com base nas relações entre sociedade e natureza.

No caso analisado, as discussões sobre a unidade de conservação refletem as dimensões jurídico-política e natural. A dimensão jurídico-política permite tratar da ação estatal que resultou na criação do PNMR. Mondardo (2011) declara que na referida dimensão o território é visto como um espaço sobre o qual se exerce um determinado poder. Já a dimensão natural favorece as abordagens sobre as características do parque nacional. Segundo Little (2006), as unidades de conservação de proteção integral podem ser consideradas territórios em função da centralidade do controle sobre essas áreas, as pesquisas desenvolvidas e o zoneamento que determinada as ações permitidas ou vedadas. Dantas e Morais (2008) percebem esses territórios como naturais, por proibir as intervenções e mobilidade humanas.

Nas discussões sobre o território do povo Ingarikó, as dimensões cultural e econômica se mostram mais apropriadas. Para Garcia (1976) e Haesbaert (2010), a dimensão cultural pode propiciar o desvendamento de códigos culturais e os anseios tanto materialistas quanto idealistas envolvidos na construção do território. $\mathrm{Na}$ mesma perspectiva, a dimensão econômica se aplica ao território indígena quando o espaço vivido é tratado como fonte de recursos.

As quatro dimensões se revelam importantes na análise da área sobreposta em razão das territorialidades estatais e indígenas envolvidas. Little (2002) percebe a territorialidade como o empreendimento de esforços de um grupo social para a apropriação de determinada porção do espaço. A apropriação compreende as ações de ocupação, uso, controle e identificação, capazes de converter o espaço defendido em território.

Além das referidas territorialidades, as dimensões mencionadas também indicam a construção de dois tipos de territórios reunidos por superposição. A unidade de conservação foi criada pela ordem social dominante, resultante do poder estatal sobre o território nacional denominado por Guattari (1985) como espaço liso. Já o homeland indígena se viu inserido no espaço liso, transformado no que Haesbaert (2010) costuma chamar de território alternativo. 


\section{PARQUE NACIONAL DO MONTE RORAIMA E OS DETERMINANTES DA CONSERVAÇÃO DA NATUREZA}

O PNMR foi criado pelo Programa Nossa Natureza, por meio do Decreto no 97.887, de 28 de junho de 1989. Segundo Brasil (2004, p. 3), o Monte Roraima dispõe de uma das paisagens mais exóticas do mundo. A rocha desnuda, pobre em minerais e nutrientes e com "radiação solar e temperaturas extremadas", propicia o desenvolvimento de mecanismos de especial adaptação da fauna e da flora.

A despeito da importância ecológica, as paisagens encontradas na área de pesquisa não podem ser consideradas estritamente naturais. Bensusan (2004) aponta que a diversidade biológica de determinada área resulta da interação entre as pessoas e o ambiente. As paisagens da região suscitam, portanto, discussões a respeito dos fatores que propiciaram a conservação da biodiversidade, mantendo os recursos disponíveis para a utilização direta ou indireta. Torna-se possível destacar três fatores relevantes na conservação dos bens naturais: o modo de vida indígena, a incidência da região na faixa de fronteira e a existência de terras sagradas.

Quanto ao modo de vida indígena, Diegues e Arruda (2001) ressaltam que quando uma sociedade indígena se apoia num modelo de produção précapitalista, suas prioridades costumam se restringir à reprodução cultural, incluindo as relações harmônicas com o ambiente. No caso analisado, o estado de conservação da biodiversidade encontrado no período de criação do PNMR serviu para atestar as relações harmônicas entre os Ingarikó e o ambiente até aquele momento.

Em relação à incidência da região na faixa de fronteira, Bourliére (2005) ressalta que as fronteiras entre os estados nacionais são marcadas em grande parte por barreiras naturais. Para Andersen (2011), esse tipo de região costuma ser caracterizada pela dificuldade de acesso e baixa densidade demográfica. A linha de fronteira norteada pelo divisor de águas, conforme Silva (2005), comporta as três características citadas.

Já as áreas sagradas resultam do processo histórico de construção e produção do território. Tal processo culminou com a definição das áreas montanhosas como terras sagradas. O etnomapa elaborado pelo povo Ingarikó fornece indicações sobre as porções do território consideradas sagradas (Figura 2). 
Figura 2 - Etnomapa elaborado pelo povo indígena Ingarikó

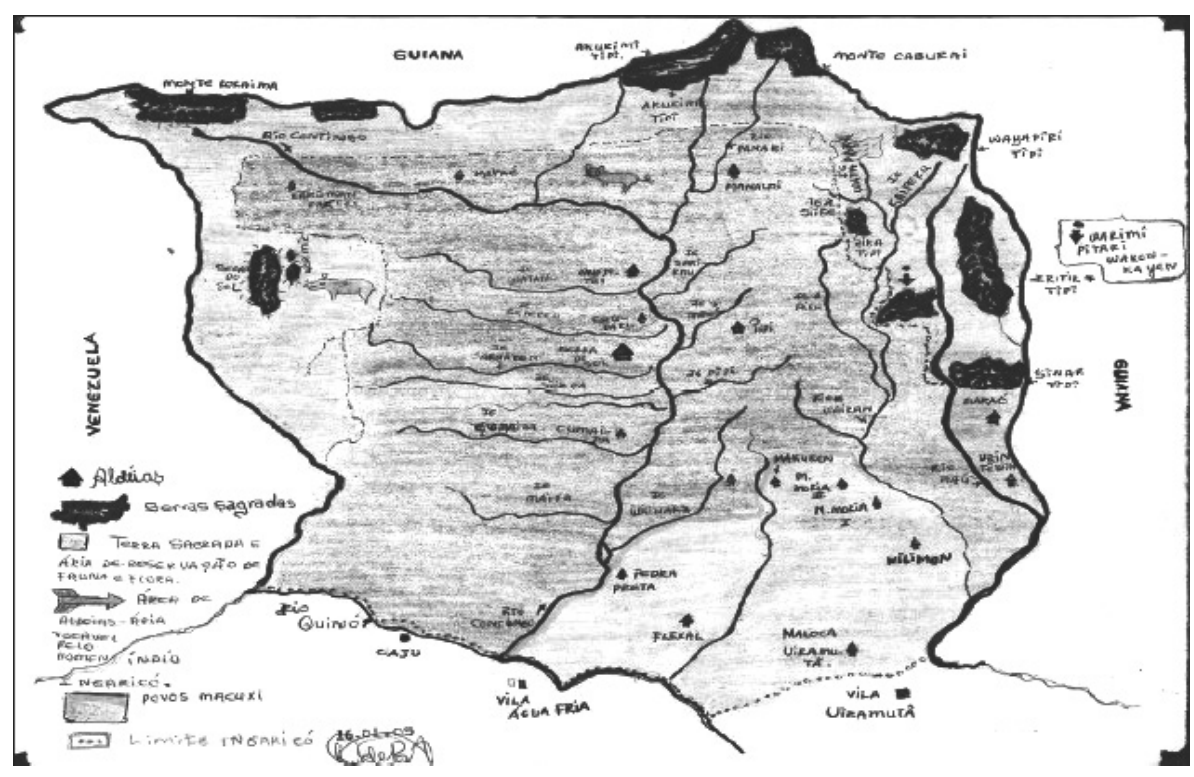

Fonte: Brasil (2012).

Os espaços considerados sagrados, definidos a partir de critérios culturais, implicam em restrição de acesso e utilização de recursos, constituindo as áreas mais conservadas, do ponto de vista ecológico. Coincidentemente, as terras sagradas foram incluídas na área do PNMR por ocasião do seu processo de criação.

Nota-se que a criação de um parque nacional na faixa de fronteira contraria a doutrina das fronteiras vivas adotadas pela defesa nacional. Segundo as concepções geopolíticas nacionais, as fronteiras devem permanecer ocupadas. Porém, a ocupação indígena foi considerada preocupante, suscitando a busca de alternativas. A opção encontrada comportou um viés tanto político quanto geopolítico, representado pela unidade de conservação. Segundo Silveira (2010) a criação do PNMR resultou da preocupação do então presidente José Sarney com a segurança nacional, o desenvolvimento econômico e a cobiça internacional sobre a região amazônica.

\section{MULTITERRITORIALIDADE NO PARQUE NACIONAL DO MONTE RORAIMA}

A multiterritorialidade da área estudada envolve basicamente o povo Ingarikó e o poder público. A territorialidade desse último incide sobre a área por meio do domínio sobre o espaço liso, a faixa de fronteira e a unidade de 
conservação. Essas três territorialidades do poder público envolvem o Estado Nacional, a Defesa Nacional e o Instituto Chico Mendes de Conservação da Biodiversidade (ICMBio).

Embora não seja possível precisar o início da ocupação protagonizada pelo povo Ingarikó, Cruz (2005) menciona que a construção do território resultou das estratégias de afastamento dos conflitos interétnicos ocorridos no entorno do Monte Roraima. Ao discorrer sobre os Ingarikó, Koch-Grunberg (2006) destacou o espírito guerreiro do grupo, envolvido em vários conflitos relacionados à defesa do seu território. Dessa forma, torna-se possível conceber que a área estudada constituiu, a priori, um território cultural, produto da apropriação simbólica, e econômico, no sentido de território como fonte de recursos.

Já a territorialidade do Estado Nacional, em termos de controle do espaço liso, iniciou-se com os portugueses, envolvendo a definição das fronteiras com as nações vizinhas e as ações administrativas sobre a área. Em suas considerações, Becker (2004) destacou a atuação da diplomacia nas relações internacionais e o controle interno do território.

Também integrante do poder público, a territorialidade da defesa nacional passou a incidir sobre a área superposta por se tratar de uma faixa de fronteira. Os limites localizados ao norte e a oeste coincidem com a linha de demarcação que separa o Brasil da Guiana e da Venezuela. Segundo Andersen (2011), a faixa de fronteira constitui uma zona específica de segurança, situada dentro do território nacional e ao longo das fronteiras. A definição da faixa de fronteira, fixada pela Constituição de 1988 em 150 quilômetros, envolve toda a área do PNMR. Diante dessa condição, intervenções do poder público na área não podem ser descartadas, visto que para a geopolítica clássica a fronteira é considerada um dos mais importantes elementos de uma nação.

Outra vertente da territorialidade do poder público corresponde ao PNMR, sendo representada pelo ICMBio, órgão responsável por sua gestão. A partir da publicação da Lei n⿳⺈ 11.516, de 28 de agosto de 2007, o ICMBio substituiu o Instituto Brasileiro de Meio Ambiente e Recursos Naturais Renováveis (IBAMA) na administração das unidades de conservação federais.

A multiterritorialidade formada pelos indígenas e pelo poder público enseja uma sobreposição de governanças no sentido defendido por Silva, Lima e Elias (2006). A despeito dos diferentes interesses sobre a área superposta, os conflitos identificados nesse estudo se concentram nas territorialidades representadas pelo povo Ingarikó e pelo ICMBio. 
De modo geral, os conflitos podem ser definidos como tensões produzidas pela presença simultânea de motivos contraditórios. Segundo Nascimento e Sayed (2012, p. 48), o termo conflito indica um "processo onde uma das partes percebe que a outra parte frustrou ou irá frustrar seus interesses".

Little (2006) estabelece dois estágios intercambiáveis dos conflitos socioambientais: o manifesto e o latente. Quando ocorre o acirramento das tensões, os conflitos socioambientais se tornam manifestos. Depois de algum tempo, pode ocorrer um apaziguamento e as tensões se tornarem latentes. Como não existe possibilidade de resolução completa do conflito sem a eliminação da sua causa, conforme defende Regalia (2012), o estágio latente não desaparece totalmente, podendo evoluir novamente para um conflito manifesto.

\section{COMPLEXIDADE DA SOBREPOSIÇÃO DE DIREITOS E SUAS IMPLICAÇÕES PARA OS ENVOLVIDOS}

Qualquer discussão a respeito da sobreposição de territórios conduz a questões relacionadas aos direitos dos envolvidos. Nesse caso, os direitos em contraste pertencem aos domínios ambiental e indígena. Barral e Ferreira (2006) consideram o surgimento das normatizações relacionadas com a questão ambiental uma resposta à intensificação da interferência humana na natureza. A partir da década de 1970, percebe-se a priorização dos esforços para interferir nas agendas políticas. Uma conquista importante foi a inserção de um artigo voltado à proteção do meio ambiente na Constituição Federal de 1988.

A política ambiental brasileira comporta três segmentos considerados basilares da sua composição: as políticas indutoras, regulatórias e estruturadoras. Segundo Boeira (2004), as políticas indutoras constituem estratégias destinadas à persuasão dos indivíduos e grupos por meio de linhas especiais de financiamento ou políticas fiscais e tributárias. Já as políticas regulatórias envolvem a implementação de normas. Para Gutierrez (2008), trata-se de um conjunto de regras ou ações impostas pelo poder público, visando à proteção da qualidade ambiental no território nacional. Conforme Boeira (2004), as políticas estruturadoras correspondem às intervenções diretas do poder público na proteção da qualidade ambiental.

No Brasil, o desenvolvimento das políticas estruturadoras teve início com as propostas de criação de parques nacionais e estaduais, além da declaração de algumas áreas como florestas protetoras, no ano de 1934. Merecem destaques, também, as ações desenvolvidas na década de 1980, tais como a promulgação da Lei n⿳o 6.938 de 31 de agosto de 1981, que estabelece a Política Nacional do Meio 
Ambiente. A partir de 1988, ano da promulgação da Constituição da República Federativa do Brasil, outras unidades de conservação são criadas.

No tocante às discussões sobre os direitos indígenas, torna-se necessário abordar determinados aspectos da formação do estado moderno. Ao considerar que o Estado nascido de uma constituição se transforma no centro compilador dos interesses do indivíduo, Silveira (2010) declara que o mesmo estabelece antagonismos com as sociedades primitivas. O Estado se recusa a interagir com as comunidades que não se adaptam às suas diretrizes. A escassez de alternativas disponíveis a determinadas minorias se reflete, inclusive, no direito de autodeterminação, vista com ressalvas pelo poder público.

Brasil (2012) ressalta a existência de instrumentos legais voltados aos índios desde o século XVI. Porém, somente com a criação do Serviço de Proteção ao Índio (SPI) alguns princípios indigenistas importantes foram estabelecidos. A despeito dos diversos problemas institucionais, algumas ações envolveram a prevenção de coerções ou outras formas de violência praticadas contra os indígenas.

Com a substituição do SPI pela Fundação Nacional do Índio (Funai), em 1967, e a publicação da Lei 6.001 de 1973, que dispõe sobre o Estatuto do Índio, alguns avanços foram registrados em termos de direitos. Porém, somente com a Constituição de 1988 os direitos indígenas foram adequadamente reconhecidos.

As determinações da Constituição de 1988 favoreceram o reconhecimento dos territórios do povo Ingarikó e outras quatro etnias situadas entre os limites da TIRSS. Segundo Santilli (2001), Lauriola (2004) e Frank e Cirino (2010), as primeiras iniciativas relacionadas à destinação de uma área na região da Raposa e da Serra do Sol para os povos indígenas foram iniciadas em 1917. Outras ações foram empreendidas a partir de 1919 pelo SPI e após 1976, por iniciativa da Funai. A partir do ano de 1996, diversos embates no âmbito jurídico refletiram a luta dos povos indígenas e seus apoiadores no processo de demarcação da TIRSS, culminando com a homologação pelo Decreto de 15 de abril de 2005. O mesmo instrumento jurídico reconheceu a sobreposição entre o povo Ingarikó e o PNMR e determinou a gestão conjunta da área duplamente afetada.

Alguns anos depois, diante da contestação da demarcação, coube ao Supremo Tribunal Federal (STF) julgar a Petição 3388, relacionada com a demarcação da TIRSS. Embora o STF tenha determinado a validade da demarcação, impôs dezenove condicionantes. Uma delas elevou o órgão ambiental à condição de único responsável pela gestão do PNMR, oferecendo novos contornos aos conflitos entre os direitos ambiental e indígena na área sobreposta.

Nesse novo contexto, nove tipos de conflitos foram estabelecidos. No período compreendido entre os anos 1999 e 2005, os conflitos atingiram o 
estágio classificado por Little (2006) como manifesto, provocado pelo impacto da informação sobre a existência de um parque nacional entre os Ingarikó. Após esse período, com as aproximações entre as partes envolvidas, os conflitos aqui abordados passaram para um estágio denominado pelo autor como latente.

\section{a) Conflito I: criação do PNMR em território indígena}

Para reforçar o domínio em uma linha de fronteira internacional, o governo decidiu criar uma unidade de conservação de proteção integral no território indígena. A implementação da política pública preservacionista demandou uma estratégia capaz de evitar a resistência indígena. A opção pela invisibilização indígena logrou êxito em evitar a oposição dos autóctones à gênese da PNMR.

A invisibilização mencionada pode ser caraterizada pela recusa do poder público em reconhecer o que Mota e Galafassi (2009) percebem como um vínculo histórico entre os indígenas e o seu território. Para Rodrigues (2013), o povo Ingarikó foi invisibilizado étnica, política e geograficamente em diversos momentos da sua história. O período de criação do PNMR se inclui entre esses momentos.

Para Honneth e Margalit (2015), esse tipo de invisibilidade possui um sentido tanto real quanto figurado, marcado pela recusa em ver aquilo que foi nitidamente percebido. Simim (2015) defende a existência de dois momentos nesse processo de invisibilidade. Num primeiro plano, existe a completa percepção da pessoa ou grupo. Depois ocorre a decisão de não ver.

Essa atitude pressupõe uma intencionalidade, vista por Tomás (2008) como a estrutura essencial da consciência que visa dar significado ao que os olhos percebem. Sendo a consciência a doadora de sentido, o ato de ver se transforma numa operação ou mesmo numa criação. Nesse sentido, a percepção se pauta por motivações, vendo ou se recusando a ver de forma intencional. Em um mundo marcado pela atribuição de diferentes níveis de importância ao que se observa, a experiência subjetiva se torna a única responsável por conferir objetividade à realidade.

Na criação do PNMR, a subjetividade do poder público passou a conduzir a sua própria objetividade, revelando uma atitude consciente e intencional de não ver o povo Ingarikó. Esse comportamento se ajustou às ideias de Cittadino (2005) sobre o invisibilizador se apoiar em sua condição de poder dominante para praticar a invisibilização. Em suas ações relativas ao parque nacional, o poder público lançou sobre os indígenas o que Merigueti (2017) ilustra como um véu imaginário, tornando os autóctones invisíveis aos olhos governamentais. 
Ao configurar uma atitude de invisibilização, a ação estatal também se enquadrou naquilo que Carleheden, Heidegren e Willig (2012) e Honneth e Margalit (2015) percebem como um flagrante desrespeito. A falta dos sinais de reconhecimento levou o povo Ingarikó a acreditar na própria invisibilidade perante o poder público. Segundo Buril (2017), a crença na própria invisibilidade decorre da falta de ações e reações daquele que invisibiliza. Para o autor, a parte vitimada não consegue acreditar na sua visibilidade quando as atitudes do invisibilizador atestam que a percepção não ocorreu.

A postura do poder público impediu as necessárias aproximações e negociações sobre a aceitação da unidade de conservação pelos indígenas e o enfrentamento da conciliação entre a proteção integral e o usufruto indígena. Os diálogos poderiam ter resultado num acordo sobre a categoria de manejo mais apropriada e a forma de participação indígena no processo de gestão, formando parceria na administração da área duplamente afetada.

Rejeitando essas possibilidades, o poder público teve os trâmites relativos à gênese facilitados, mas acumulou maiores dificuldades ao processo de gestão dessa situação não resolvida. A necessidade de tratar de assuntos que deveriam ter sido esgotados no processo de criação do PNMR passou a tomar o tempo, os recursos e os esforços demandados pela conservação da biodiversidade, desafiando a gestão do parque nacional.

Além da tensão estabelecida com o povo Ingarikó, outros problemas foram desencadeados junto aos demais povos da TIRSS. Para esses últimos, a criação do PNMR foi interpretada como um novo obstáculo ao processo de demarcação da TIRSS e a autonomia desses povos. Ao tomarem conhecimento da visão dos povos Patamona, Wapixana, Macuxi e Taurepang sobre a criação do referido parque nacional, alguns autores buscaram analisar a legalidade do ato do poder executivo.

Para Lauriola (2010), a criação do referido parque nacional contrariou o artigo 231 da Constituição, que determina a nulidade de qualquer ato visando a posse, propriedade ou exploração dos bens naturais em territórios indígenas. Em uma perspectiva diferente, Scardua (2004) lembra da ressalva constante no mesmo artigo sobre a possibilidade de respaldo dos atos de interesse do poder público por lei complementar. Nessas condições, tanto a homologação da TIRSS quanto a criação do PNMR apresentam consistências jurídicas que inviabilizam questionamentos sobre os decretos de homologação e criação, respectivamente.

Em meio ao impasse, representantes do órgão ambiental responsável pela gestão do PNMR conseguiram se aproximar do povo Ingarikó. Aproveitando os diálogos, passaram a apoiar a criação do Conselho o Povo Ingarikó (COPING) 
no ano de 2003 e participar das assembleias gerais promovidas pelos indígenas. Depois da homologação da TIRSS, começaram a tratar do plano de gestão conjunta com os Ingarikó e a Funai, seguindo a determinação constante no Decreto de 15 de abril de 2005.

A despeito das aproximações entre as partes, as tensões provocadas pela criação do PNMR em território indígena se revelaram desafiadoras por contrapor a proteção integral ao usufruto indígena. Tais estratégias de gestão territorial podem ser consideradas mutuamente excludentes em função das suas respectivas naturezas. Essa reunião forçada de estratégias diferentes se tornou uma fonte de tensões entre as partes envolvidas.

b) Conflito II: durante a definição dos limites do PNMR, uma comunidade indígena e a área de residência de uma família, anteriormente estabelecidas, foram incorporadas à área do parque nacional

Em virtude da atitude de invisibilização do poder público contra os Ingarikó, o centro comunidade Mapaé e a localidade conhecida como Cachoeira da Onça, habitada por uma família, foram incorporadas aos limites do PNMR. Essa situação estabeleceu limitações à aplicação da legislação específica para os parques nacionais. Uma das razões consiste no contraste entre a legislação ambiental e os direitos indígenas, estes últimos respaldados por instrumentos jurídicos tais como a Constituição Federal, o Estatuto do Índio e outros.

Sendo inevitáveis as intervenções indígenas nos centros das comunidades, especialmente num contexto de crescimento populacional, a iniciativa do poder público provocou o aumento da dificuldade de conciliação entre as partes envolvidas na sobreposição por contrastar mais fortemente o usufruto indígena e a proteção integral.

Conforme as declarações de um servidor do ICMBio, os conflitos envolvendo as comunidades residentes no PNMR constituem um tipo de tensão classificada como conflito latente, no sentido defendido por Little (2006). Envolve, portanto, as tensões percebidas, mas não manifestadas abertamente. No caso do PNMR, a não manifestação pode constituir uma estratégia de gestão.

c) Conflito III: sobreposição das legislações ambiental e indígena na áreaduplamente afetada

A opção pela invisibilização indígena também desencadeou uma sobreposição de direitos. Embora a criação de unidades de conservação e 
o reconhecimento de territórios indígenas sejam ações constitucionais, sua sobreposição provoca o estabelecimento de tensões não previstas no conjunto do direito brasileiro. Nessas condições, os conflitos acabam se manifestando no cotidiano do processo de gestão da área.

Serve como exemplo a questão do usufruto em unidade de proteção integral. Segundo Santilli (2004), embora o Decreto n⿳ำ 6.514, de 22 de julho de 2008, determine que os indígenas são passíveis de responsabilização criminal, a Constituição Federal reconhece a organização social, costumes, crenças e tradições dos povos originários, além dos direitos sobre o território que tradicionalmente ocupam.

A prevalência da legislação ambiental sobre a indígena na área do PNMR tende a afetar a autonomia indígena. Conforme os depoimentos das lideranças indígenas, a autonomia percebida pelas comunidades envolve três esferas: política, educacional e física, duas delas estreitamente relacionadas com a sobreposição de direitos. A esfera política comporta a liberdade de conceber, idealizar, decidir etc. Relaciona-se, portanto, com as declarações de Lalande (1999) quando faz alusão a uma coletividade cultural que determina as leis às quais se submete. A esfera física envolve a subsistência das comunidades Ingarikó. A autonomia foi definida pelo líder Dílson Domente Ingaricó como a “autodefinição como um povo, com saber próprio e com tecnologia de produção própria”. Durante um período de aproximadamente dez anos, a autonomia indígena foi restringida "legalmente" pela territorialidade estatal sem nenhuma comunicação prévia, confirmando a situação de invisibilização. Os primeiros indícios das restrições foram vislumbrados a partir das determinações do plano de manejo do PNMR. No zoneamento contido no plano de manejo, algumas áreas com elevada restrição coincidiram com os geossímbolos dos Ingarikó.

Tem locais sagrados que nós nunca pegamos um objeto. É reservado mesmo. Naqueles locais a gente não pode mexer. Até os pajés, espiritualmente dizem que não pode mexer. Então o que está localizado ali a gente não pode mexer, nem neto, nem bisneto. Se acabar com os locais sagrados, vai acontecer uma série de coisas: chover bastante, vai ter alagamento, seca... Para não acontecer isso a gente sempre preserva (GELSON JOSÉ MARTINS, entrevista realizada no dia 16 de agosto de 2012).

Todavia, as restrições propostas pelo plano de manejo também atingem áreas de maior usufruto, sendo cada vez mais importantes num contexto de crescimento populacional (Tabela 1). Convém mencionar que a ausência de alguns dados se justifica pelo não fornecimento das informações por parte da 
FUNASA/CIR e, posteriormente SESAI-DSEI Leste, ou ao surgimento de novas comunidades, como é o caso das comunidades Awendei, Paraná, Área Única, Kumaipá e Pamak.

Tabela 1 - Comunidade e população da área Ingarikó - TIRSS

\begin{tabular}{l|c|c|c|c|c}
\hline Comunidades & $\mathbf{2 0 0 0}$ & $\mathbf{2 0 0 5}$ & $\mathbf{2 0 1 0}$ & $\mathbf{2 0 1 5}$ & $\mathbf{2 0 1 6}$ \\
\hline Serra do Sol & 291 & 323 & 427 & 343 & 403 \\
\hline Sauparú & 90 & 85 & 100 & 45 & 48 \\
\hline Pipi & 23 & 30 & 23 & 37 & 43 \\
\hline Manalai & 282 & 325 & 351 & 402 & 417 \\
\hline Mapaé & 109 & 133 & 351 & 189 & 198 \\
\hline Awendei* & - & 24 & 75 & 87 & 98 \\
\hline Paraná** & & & 33 & 49 & 54 \\
\hline Área Única*** & & & - & 74 & 79 \\
\hline Kumaipá**** & & & & 156 & 186 \\
\hline Pamak (Mucajai)**** & & & & 47 & 50 \\
\hline
\end{tabular}

Fonte: Conselho Indígena de Roraima/CIR; Fundação Nacional de Saúde/FUNASA (Período 2000 a 2010); Secretaria Especial de Saúde Indígena-SESAI - Brasil (2017)

* Comunidade criada em 2002 com 23 moradores

** Comunidade criada em 2006 com 30 moradores

*** Comunidade criada em 2007 com 42 moradores; no ano de 2010 não existe registro da população pelo SESAI

**** Sem dados para indicar a criação da comunidade.

O crescimento populacional tem provocado o aumento da demanda por bens naturais em áreas definidas no plano de manejo como altamente restritas, nas quais o simples acesso é vetado aos indígenas. Nessa circunstância, a sobreposição das legislações ambiental e indígena confere grande dificuldade à conciliação entre as partes.

d) Conflito IV: limitações impostas pelas condicionantes do STF à territorialidade indígena

Após o empreendimento de uma luta por reconhecimento pautada em estratégias de representação, negociação e resistência, os Ingarikó lograram a visibilização da sua territorialidade. A superação da invisibilização territorial ficou demonstrada no Decreto de 15 de abril de 2005, no qual o poder público reconheceu a sobreposição entre o PNMR e a TIRSS e determinou a gestão conjunta da área duplamente afetada. Segundo Brasil (2005), o governo também vislumbrou a necessidade de administração tripartite, envolvendo os órgãos ambiental e indigenista e o povo Ingarikó. 
No entanto, quatro anos depois o STF retirou dos indígenas o empoderamento anteriormente concedido ao determinar que o órgão ambiental seria o único responsável pela gestão da área sobreposta. Embora o Decreto $\mathrm{n}^{\mathrm{o}}$ 7.747, de 5 de junho de 2012, que instituiu a Política Nacional de Gestão Territorial e Ambiental de Terras Indígenas (PNGATI) tenha restaurado a necessidade de negociação entre as partes, não recuperou as condições estabelecidas pelo Decreto de 15 de abril de 2005.

Curiosamente, as condicionantes do STF parecem não ter sido suficientes para transformar a tensão latente num conflito manifesto, segundo a perspectiva de Little (2006). Uma explicação possível envolve a apropriação ainda abstrata do território natural pelo ICMBio. Esse tipo de apropriação com o sentido abordado por Raffestin (1993) tem impedido que grande parte dos indígenas constate de forma prática as limitações impostas pelas condicionantes.

Segundo um tuxaua da comunidade Awendei, o PNMR nunca limitou suas ações na área sobreposta. Ainda assim, o líder ressaltou a disposição dos Ingarikó em lutar pela defesa de seus interesses tão logo se sintam cerceados em suas atividades cotidianas na área também afetada ao PNMR. Enquanto a apropriação segue abstrata, as lideranças têm se mostrado dispostas a dialogar com o órgão ambiental na tentativa de encontrar soluções conciliadoras.

e) Conflito V: restrições à reprodução física das comunidades indígenas na área sobreposta ao parque nacional

A despeito da superação da invisibilização no tocante à territorialidade, as condicionantes do STF suscitaram a prevalência do plano de manejo do PNMR sobre quaisquer documentos relacionados à gestão da área duplamente afetada. Legalmente, isso implicou na observância das determinações do plano de manejo do PNMR. Segundo Brasil (2000), o referido documento define 51,27\% da área do parque nacional como zona intangível e 37,06\% como primitiva. Na zona intangível são vedadas quaisquer alterações humanas, em razão da sua condição de matriz de repovoamento de outras zonas. Já na zona primitiva, embora sejam admitidas atividades de uso público, a abertura de trilhas não é permitida.

A soma das porcentagens de ocupação das referidas zonas alcança um total de $88,33 \%$ da área sobreposta. Diante de qualquer reivindicação do povo Ingarikó, as condicionantes do STF também oferecem apoio aos interesses da territorialidade estatal quando determinam que as comunidades indígenas devem ser ouvidas (apenas ouvidas). A decisão final cabe, portanto, ao ICMBio. Por se tratar de uma área prioritária para a conservação, a instituição citada deve acatar 
as determinações do Plano de Manejo. Caso as comunidades indígenas decidam extrair recursos da zona intangível para sua reprodução física, em atendimento à demanda crescente de recursos para subsistência, devem frustrar os interesses da territorialidade estatal, desencadeando conflitos, além de provocar a elevação das tensões em razão dos contrastes entre o usufruto indígena e a proteção integral.

f) Conflito VI: limitações à reprodução cultural das comunidades indígenas

A construção do território indígena pressupõe a criação de referenciais espaciais e a importância da área duplamente afetada remonta à criação de símbolos que fortalecem a identidade dos Ingarikó. Os depoimentos de lideranças indígenas, tais como os proferidos pelo senhor Alberto Cretáceo, refletem a criação de símbolos: "existem locais que eram muito bravos (escurecia, chovia bastante). As cachoeiras são muito sagradas, a gente não pode pisar lá porque começa a chover, ventar... Os locais sagrados são raízes do mundo". A construção do território indígena resulta da criação de símbolos, associados à noção do sagrado para os Ingarikó. A apropriação do território tem sido definida por um processo de identificação cultural, baseado no apego ao lugar vivido.

As limitações impostas pelo plano de manejo do PNMR obstaculizam o desenvolvimento de pensamentos, ações e da própria vida ao interferirem no processo de identidade do povo Ingarikó. Nesta esteira, a apropriação concreta do território natural pelas condutas da territorialidade estatal nos moldes estabelecidos no manejo implicaria em limitações à reprodução cultural do povo indígena Ingarikó.

g) Conflito VII: obstáculos aos processos de negociação e estabelecimento de parcerias

Para analisar os obstáculos ao processo de negociação entre as partes, torna-se necessário abordar os principais aspectos das relações entre o povo Ingarikó e o ICMBio. Inicialmente, merece reflexão a questão da disposição de cada parte ao diálogo. Nesse particular, as partes sempre se mostraram dispostas a dialogar.

A participação em eventos permite a constatação de que as assembleias constituem o único fórum de decisões estratégicas do povo Ingarikó. A participação massiva das comunidades indígenas demonstra a relevância dessas assembleias como fórum de decisões coletivas. A presença de representantes do órgão ambiental em alguns eventos promovidos pelo povo Ingarikó tem facilitado 
o diálogo entre as partes, porém, nem sempre conseguem participar, como nos anos de 2009 e 2010. Os motivos costumam ser alheios à vontade dos servidores.

Convém então verificar as condições nas quais o processo de negociações tem se desenvolvido. A despeito dos obstáculos impostos pelo STF no ano de 2009, três anos depois a PNGATI restaurou a necessidade de negociações entre as partes. O novo empoderamento dos Ingarikó propiciou o livre exercício da autonomia, favorecendo a elaboração de um plano conjunto de gestão. Assim, também nesse ponto parece não haver dificuldade à formalização de parcerias.

A análise suscita também a questão das necessárias concessões entre as partes. Mesmo considerando os desafios das negociações envolvendo a proteção integral e o usufruto indígena, o plano de gestão compartilhada submetido à apreciação do ICMBio demonstra as diversas concessões feitas pelos envolvidos. As concessões foram efetuadas durante o processo de diálogos entre o povo Ingarikó e a equipe local do ICMBio. Embora os envolvidos tenham superado o obstáculo das concessões, a aprovação do plano foi impedida por outras instâncias do órgão ambiental.

h) Conflito VIII: ao contrário do povo ingarikó, os servidores do PNMR não possuem autonomia para tomar decisões e ou firmar acordos sem a autorização do ICMBIO-Sede

No que se refere à autonomia de decisão entre os envolvidos, geralmente os indígenas se apresentam para as negociações com todas as suas instâncias de decisão, enquanto o ICMBio participa por meio de representantes. Após o consenso local, o documento construído precisa ser encaminhado pelos representantes do órgão ambiental a outras instâncias. Quando os técnicos analisam as propostas, acabam recorrendo à legislação ambiental para suprir a inexistência de normas específicas. Como consequência, as concessões feitas pelas equipes locais durante as negociações se tornam sujeitas a reprovação. Quando isso ocorre, o documento costuma ser reenviado aos seus idealizadores para adequações impossíveis no contexto da compatibilização entre a proteção integral e o usufruto indígena.

Em âmbito nacional, os desafios à proposição de diretrizes às situações de sobreposição se estendem há quase duas décadas. No ano 2000, o artigo 57 do SNUC determinou a formação de grupos de trabalho para a formulação de diretrizes voltadas às superposições. Segundo Santilli (2005), Leuzinger (2007) e Lopes (2013), a norma encomendada em 1988, levada ao Congresso Nacional em 1992 e aprovada no ano 2000 após intensos debates não poderia se omitir 
aos casos de sobreposição. Porém, apesar das determinações do seu artigo 57, nenhuma diretriz foi proposta. O mesmo aconteceu com o Decreto $n^{\circ} 5.758$, de 13 de abril de 2006, que instituiu o Plano Estratégico Nacional de Áreas Protegidas (PNAP). O objetivo de solucionar os conflitos decorrentes da sobreposição das unidades de conservação com terras indígenas ou terras quilombolas permanece sem solução.

Nessas condições, o avanço na celebração de acordos continua carecendo de orientações internas do órgão ambiental sobre a impossibilidade de participar de negociações sem fazer concessões contrastantes com a legislação ambiental. Se os dirigentes do órgão ambiental não admitirem isso, a elaboração de planos conjuntos continuará consumindo tempo, esforços e recursos que deveriam ser dedicados à conservação da biodiversidade sem alcançar os seus objetivos.

i) Conflito IX: distinções de percepções entre a equipe local do ICMBIO e as demais instâncias administrativas

A despeito das dificuldades impostas pela estrutura administrativa do ICMBio ao processo de negociações, outras questões afetam negativamente o estabelecimento de acordos. Dentre elas, torna-se possível citar as distintas percepções dos servidores que mantêm contato direto com as comunidades indígenas e aqueles que acompanham os acontecimentos por meio da leitura de documentos. Nessa esteira, os servidores lotados no PNMR tendem a assumir uma postura mais conciliadora. Já os servidores das instâncias superiores tendem a defender posturas preservacionistas, pautadas unicamente na legislação ambiental.

As percepções obtidas in loco propiciam a identificação de peculiaridades que resultam em distinções da visão geral comumente praticada. As decisões das instâncias superiores do órgão ambiental são baseadas principalmente em relatórios, os quais não se mostram suficientes para o entendimento da complexidade das relações que se desenvolvem no cotidiano da sobreposição. Neste sentido, as distintas percepções também contribuem com o acirramento dos conflitos por gerar expectativas que não se confirmam.

\section{CONSIDERAÇÕES FINAIS}

A criação do PNMR em território indígena implicou na incidência de novas territorialidades sobre o espaço, entrelaçando territorialidades estatais e indígenas. A multiterritorialidade envolveu uma sobreposição de governanças pautada em lógicas distintas, desencadeando diversos tipos de conflitos. Nessas 
circunstâncias, o enfrentamento das tensões não se restringe à regularização das sobreposições, visto que a identificação dos interesses dos sujeitos revela a existência de outras fontes de conflitos. As tensões decorrentes dos distintos interesses, provenientes das territorialidades estatal e indígena tendem a se elevar em razão das medidas impositivas protagonizadas pelo Estado Nacional.

A invisibilização praticada pelo poder público contra os Ingarikó desencadeou tensões entre o PNMR e o povo indígena Ingarikó, implicando na necessidade de destacar alguns obstáculos à gestão de conflitos e as perspectivas vislumbradas a partir das análises efetuadas. O primeiro obstáculo corresponde à inexistência de legislações específicas para os casos de sobreposição territorial envolvendo unidades de conservação de proteção integral e terras indígenas. A despeito das determinações constantes na Lei 9.985 de 18 de julho de 2000 e no Decreto $\mathrm{n}^{\mathrm{9}}$ 5.758, de 13 de abril de 2006, em mais de uma década nenhuma diretriz foi proposta.

O segundo obstáculo remonta à necessidade de um plano de gestão capaz de abrigar os interesses do ICMBio e do povo Ingarikó, possibilidade reinaugurada pela PNGATI. Nessa perspectiva, o plano de manejo do PNMR pode se transformar em um instrumento de gestão de conflitos, abrigando o plano conjunto de gestão da área sobreposta. Dessa forma, os interesses indígenas de reprodução física e cultural podem ser reunidos aos interesses estatais de preservação da biodiversidade.

Em situação oposta, a falta de ações mais objetivas de gestão de conflitos acaba provocando o adiamento de questões importantes relativas à conservação da biodiversidade. Guardadas as devidas responsabilidades sobre os atrasos nas negociações, o órgão ambiental ainda precisa aceitar o fato de que a celebração de acordos nas circunstâncias expostas depende de concessões. Não se torna possível conciliar interesses de proteção integral e usufruto indígena pautando-se unicamente pela legislação ambiental.

Torna-se possível afirmar que os conflitos abordados podem ser enfrentados a partir da proposição de diretrizes para os casos de sobreposição e o entendimento do órgão ambiental sobre a necessidade de fazer concessões que muitas vezes contrariam a legislação ambiental. Dessa forma, os interesses indígenas de reprodução física e cultural podem ser reunidos aos interesses estatais no plano de manejo do PNMR. Tal possibilidade pode permitir o estabelecimento de processos de negociação capazes de preservar a autonomia dos envolvidos e resultar em acordos e parcerias, contribuindo significativamente para a gestão de conflitos na área sobreposta. 


\section{REFERÊNCIAS}

ANDERSEN, S. Parques naturais em faixa de fronteira: preservação ambiental e defesa nacional. In: FRAGA, N. C. Territórios e fronteiras: (re)arranjos e perspectivas. Florianópolis: Insular, 2011 p. 229-243.

BARRAL, W.; FERREIRA, G. A. Direito Ambiental e Desenvolvimento. In: BARRAL, W.; PIMENTEL, L. O (Orgs.). Direito ambiental e desenvolvimento. Florianópolis: Fundação Boiteux, 2006. p. 13-45.

BECKER, B. K. Amazônia: geopolítica na virada do III milênio. Rio de Janeiro: Garamond, 2004. 172 p.

BENSUSAN, N. Terras Indígenas: as primeiras Unidades de Conservação. In: RICARDO, F. (Org.). Terras Indígenas e Unidades de Conservação da Natureza: o desafio das sobreposições. São Paulo: Instituto Socioambiental, 2004. p. 66-72.

BOEIRA, S. L. Política e gestão ambiental no Brasil: da Rio 92 ao Estatuto da Cidade. Campinas: [s.n.], 2004. Disponível em: < http://www.anppas.org.br>. Acesso em: 29 jan. 2012.

BOURLIÉRE, F. Los parques nacionales de frontera. [S.I.]: FAO, 2005. Disponível em: <www.fao.org/docrep/24755s/24755s06.htm>. Acesso em: 16 mai. 2012. BRASIL. Ministério da Saúde. Secretaria Especial de Saúde Indígena. Distrito Sanitário Especial Indígena do Leste de Roraima. Censo populacional. Boa Vista: DSEI Leste Roraima, 2017.

Política indigenista. Museu do Índio. 2012. Disponível em: < http:/ / www.museudoindio.org.br>. Acesso em: 11 jun. 2012.

Instituto Brasileiro de Geografia e Estatística. 2010. Base cartográfica contínua do estado de Roraima. Rio de Janeiro: IBGE, 2010.

Plano Nacional de Educação em Direitos Humanos. 2009. Brasília: Secretaria Especial dos Direitos Humanos, Ministério da Educação, Ministério da Justiça, UNESCO, 2009.

Ministério do Meio Ambiente. Instituto Chico Mendes de Conservação da Biodiversidade. Plano de Administração da Área sob Dupla Afetação pelo Parque Nacional Monte Roraima e a Terra Indígena Raposa Serra do Sol - Plano Pata Eseru. ICMBio: Brasília, 2008. 54 p. 
Decreto s/n. de 15 de abril de 2005. Homologa a demarcação administrativa da Terra Indígena Raposa Serra do Sol, localizada nos municípios de Normandia, Pacaraima e Uiramutã, no Estado de Roraima. Diário Oficial da União, Brasília, DF, 18 abr. 2005.

Ministério do Meio Ambiente. Instituto Chico Mendes de Conservação da Biodiversidade. SOS Monte Roraima: Informações Gerais e Institucionais. Brasília: IBAMA, 2004. 91 p.

Lei n. 9.985, de 18 de julho de 2000. Institui o Sistema Nacional de Unidades de Conservação da Natureza e dá outras providências. Diário Oficial da República Federativa do Brasil, Brasília, DF, 19 ago. 2000.

Decreto n. 97.887, de 28 de junho de 1989. Cria o Parque Nacional do Monte Roraima e dá outras providências. Diário Oficial da República Federativa do Brasil, Brasília, DF, 29 jun. 1989.

BURIL, B. Reflexões sobre o diagnóstico da invisibilidade na teoria de Axel Honneth. 2017. Disponível em: <https://blogdosociofilo.wordpress. com>. Acesso em 13 jan. 2018.

CARLEHEDEN, M.; HEIDEGREN, C.; WILLIG, R. Recognition, social invisibility and distinktiun. Journal of Social Theory, London, v. 13, n. 1, p. 1-3, abr. 2012.

CITTADINO, G. Igualdade e "invisibilidade". Ciência Hoje, Rio de Janeiro, v. 37, p. 28-33. 2005.

CLEMENT, C. R. et al. The domestication of Amazonia before European conquest. Londres: Royal Society, 2015. 9 p.

COPING. Relatório da XII Assembleia Geral do Povo Ingarikó e VII Assembleia Geral do Conselho do Povo Indígena Ingarikó. Uiramutã: 2011. 25 p. (Documento não publicado)

CRUZ, M. O. S. Fonologia e gramática ingarikó. Amsterdam: Vrije Universiteit Amsterdam, 2005. 464 p.

DANTAS, E. M.; MORAIS, I. R. D. Território e territorialidade: abordagens conceituais. Natal: UFRN, 2008. 20 p.

DIEGUES, A. C.; ARRUDA, R. S. V. (Orgs.). Saberes tradicionais e biodiversidade no Brasil. Brasília: Ministério do Meio Ambiente, 2001. 176 p.

FARAGE, N. As muralhas dos sertões: os povos indígenas no rio Branco e a colonização. Rio de Janeiro: Paz e Terra/ANPOCS, 1991. 
FRANK, E. H. Os macuxi são mesmo do "Caribe"? Revista do Núcleo Histórico Socioambiental, Boa Vista, v. 1, n. 1, p. 11-36, ago./dez. 2007.

FRANK, E. H.; CIRINO, C. A. Des-territorialização e re-territorialização dos indígenas de Roraima: uma revisão crítica. In: BARBOSA, R. I.; MELO, V. F. (Orgs.). Roraima: homem, ambiente e ecologia. Boa Vista: FEMACT, 2010. 644 p.

GARCÍA, J. L. Antropologia del território. Madri: Taller de Ediciones, 1976.

GUATTARI, F. Espaço e poder: a criação de territórios na cidade. Espaço e Debates, São Paulo, n. 16, ano V, 1985.

GUTIERREZ, M. B. S. Desenvolvimento sustentável no MERCOSUL: a proposta de um marco regulatório. Rio de Janeiro: IPEA, 2008. Disponível em: <http://www.ipea.gov.br>. Acesso em: 07 fev. 2012.

HAESBAERT, R. O mito da desterritorialização: do fim dos territórios à multiterritorialidade. 5. ed. Rio de Janeiro: Bertrand Brasil, 2010. 395 p.

HONNETH, A.; MARGALIT, A. Invisibility: on the epistemology of recognition. Aristotelian Society, London, n. 1, v. 75, p. 111-126, jul. 2015.

KOCH-GRUNBERG, T. Do Roraima ao Orinoco. Tradução: Cristina AlbetsFranco. São Paulo: UNESP, 2006. 343 p. v. 1

LALANDE, A. Vocabulário técnico e crítico da filosofia. Trad.: Fatima Sa Correia et al. 3. ed. São Paulo: Martins Fontes, 1999. 1336 p.

LAURIOLA, V. M. Parque Nacional? Kaane? Os índios dizem não à implementação do Parque Nacional do Monte Roraima. In: RICARDO, F. (Org.). Terras Indígenas e Unidades de Conservação da Natureza: o desafio das sobreposições. São Paulo: Instituto Socioambiental, 2004. p. 422-431.

LAURIOLA, V. M. Terras Indígenas e conservação da biodiversidade na Amazônia: o caso do Monte Roraima. In: BARBOSA, R. I.; MELO, V. F. (Orgs.). Roraima: homem, ambiente e ecologia. Boa Vista: FEMACT, 2010. p. 35-66.

LEUZINGER, M. D. Natureza e cultura: direito ao meio ambiente equilibrado e direitos culturais diante da criação de unidades de conservação de proteção integral e domínio público habitadas por populações tradicionais. 2007. 258f. Tese (Doutorado em Desenvolvimento Sustentável) - Centro de Desenvolvimento Sustentável, Universidade de Brasília, Brasília, 2007.

LITTLE, P. E. Ecologia política como etnografia: um guia teórico e metodológico. Horizontes Antropológicos, Porto Alegre, v. 12, n. 25, p. 85-103, jan./jun. 2006. 
Territórios sociais e povos indígenas no Brasil: por uma antropologia da territorialidade. Brasília: UnB, 2002. 32 p.

LOPES, E. R. N. Aspectos ambientais e históricos do Sistema Nacional de Unidades de Conservação: 12 anos de implantação. Nature and Conservation, Aquidabã, v. 6, n. 2, p. 6-17, mai./out. 2013.

MERIGUETI, D. S. Da invisibilidade ao reconhecimento: o processo como instrumento de luta dos refugiados pela efetividade de seus direitos. 2017. 188 p. Dissertação (Mestrado em Direito) - Programa de Pós-Graduação em Direito Processual, Universidade Federal do Espírito Santo, Vitória, 2017.

MONDARDO, M. L. O território e suas dimensões política, cultural e econômica: um exercício analítico no sudoeste do Paraná. Revista Brasileira de Estudos Populacionais, Rio de Janeiro, v. 28, n. 1, p. 103-131, jan./jun. 2011.

MOTA, C.; GALAFASSI, B. A demarcação da Terra Indígena Raposa Serra do Sol: processo administrativo e conflitos judiciais. In: MIRAS, J. T. et al. (Orgs.). Makunaima grita: Terra Indígena Raposa Serra do Sol e os direitos constitucionais no Brasil. Rio de Janeiro: Beco do Azougue, 2009.

NABUCO, J. O direito do Brasil. São Paulo: Instituto Progresso Editorial, 1949. $285 \mathrm{p}$.

NASCIMENTO, E. M.; SAYED, K. M. Administração de conflitos. Revista Capital Humano - Coleção Capital Humano, n. 4, p. 47-56. Disponível em: <http:/ /www.someeducacional.com.br>. Acesso em: 13 jun. 2012.

RAFFESTIN, C. Por uma geografia do poder. São Paulo: Ática, 1993. 269 p.

REGALIA, I. Dicionário de política. Brasília: UnB, 2012. Disponível em: <http:/ /www.saudebucalcoletiva.unb.br>. Acesso em: 13 jun. 2012.

RODRIGUES, E. S. Economia e produção ingarikó. 2013.160 p. Dissertação (Mestrado em Antropologia Social) - Programa de Pós-Graduação em Antropologia Social, Universidade Federal de Pernambuco, Recife, 2013.

SANTILLI, J. Socioambientalismo e novos direitos: proteção jurídica à diversidade biológica e cultural. Brasília: Instituto Socioambiental, 2005. 155 p.

A lei de crimes ambientais se aplica aos índios? In: RICARDO, F. (Org.). Terras Indígenas e Unidades de Conservação da Natureza: o desafio das sobreposições. São Paulo: Instituto Socioambiental, 2004. 24-25 p. 
SANTILLI, P. Pemongon Patá: território Macuxi, rotas de conflito. São Paulo: UNESP, 2001. 227 p.

SANTOS, M. Metamorfoses do espaço habitado: fundamentos teóricos e metodológicos da Geografia. 6. ed. São Paulo: EDUSUP, 2008. 131 p.

SCARDUA, F. P. Manejo sustentável no Parna do Monte Roraima e na TI Raposa/Serra do Sol. In: RICARDO, F. (Org.). Terras Indígenas e Unidades de Conservação da Natureza: o desafio das sobreposições. São Paulo: Instituto Socioambiental, 2004. p. 432-435.

SILVA, J. B.; LIMA, L. C.; ELIAS, D. Panorama da geografia brasileira. São Paulo: Annablume, 2006. 368 p.

SILVA, P. R. F. Roraima no contexto regional fronteiriço: Brasil - Venezuela Guiana. In: ENCONTRO DE GEÓGRAFOS DA AMÉRICA LATINA, 10., São Paulo. Anais... São Paulo: EGAL, 2005.

SILVEIRA, E. D. Meio ambiente, terras indígenas e defesa nacional: Direitos Fundamentais em Tensão na Amazônia Brasileira. Curitiba: Juruá, 2010. 312 p.

SIMIM, T. A. Invisibilidade social a partir do filme "O som ao redor": uma análise honnethiana das patologias sociais no Brasil. Ciências Sociais Unisinos, São Leopoldo, v. 51, n. 1, p. 52-60, jan./abr. 2015.

TOMÁS, J. C. S. P. A invisibilidade social: uma perspectiva fenomenológica. In: CONGRESSO PORTUGUÊS DE SOCIOLOGIA, 6. Lisboa. Anais... Lisboa: UNL, 2018. 
